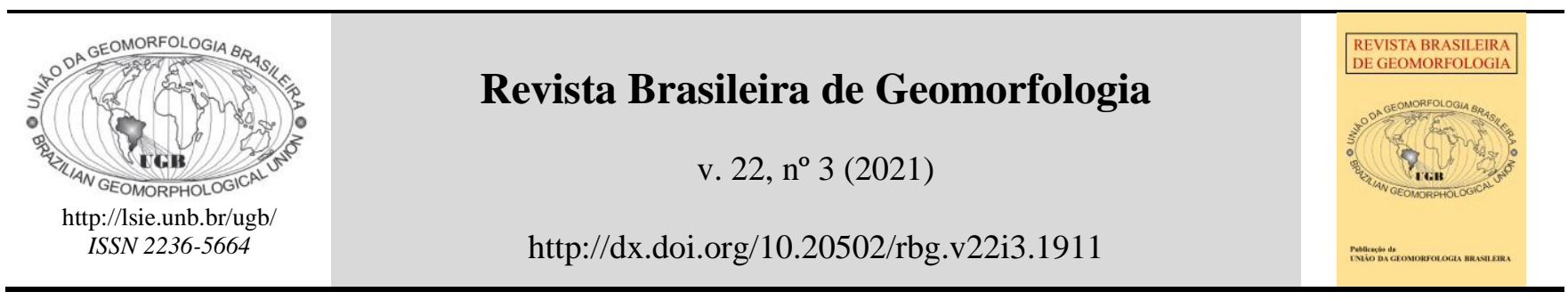

Artigo de Pesquisa

\title{
Mudanças recentes (1988-2018) em áreas livres de gelo nas ilhas Nelson e Rei George, Antártica Marítima
}

\author{
Recent changes (1988-2018) in ice-marginal environments of the King \\ George and Nelson Island ice-free land areas, Maritime Antarctica
}

\author{
Manoela Araujo Gonçalves de Oliveira ${ }^{(1)}$, Kátia Kellem da Rosa(2), Carina Petsch ${ }^{(3)}$, Rosemary Vieira( ${ }^{(4)}$ Felipe \\ Casanova(5), Jefferson Cardia Simões $^{(6)}$ \\ 1 Centro Polar e Climático, Programa de Pós-Graduação em Geografia - UFRGS, Porto Alegre, RS, Brasil. \\ manuella.araujo@hotmail.comＯRCID: https://orcid.org/0000-0003-4661-7316 \\ 2 Departamento de Geografia, Centro Polar e Climático, Programa de Pós-Graduação em Geografia - UFRGS, Porto Alegre, \\ RS, Brasil. katiakellem@gmail.comＯRCID: https://orcid.org/0000-0003-0977-9658 \\ ${ }^{3}$ Departamento de Geociências - UFSM, Santa Maria, RS, Brasil. Centro Polar e Climático, UFRGS, Porto Alegre, RS, Brasil. \\ carinapetsch@gmail.com ORCID: http://orcid.org/0000-0002-1079-0080 \\ ${ }^{4}$ Laboratório de Processos Sedimentares e Ambientais, Depto de Geografia - UFF, Niterói, RJ, Brasil \\ rosemaryvieira@id.uff.br ORCID: https://orcid.org/0000-0003-0312-2890 \\ ${ }^{5}$ Centro Polar e Climático, UFRGS, Porto Alegre, RS, Brasil, felipe.casanova2018@outlook.com ORCID: \\ https://orcid.org/0000-0002-3626-7853 \\ 6 Departamento de Geografia, Centro Polar e Climático, Programa de Pós-Graduação em Geografia - UFRGS, Porto Alegre, \\ RS, Brasil. jefferson.simões@ufrgs.br ORCID: https://orcid.org/0000-0001-5555-3401
}

Recebido: 11/12/2020; Aceito: 17/05/2021; Publicado: 01/07/2021

\begin{abstract}
Resumo: O objetivo deste trabalho é comparar as variações dos lagos e geleiras apresentadas por diferentes setores de áreas livres de gelo nas ilhas Rei George (IRG) e Nelson (IN) no período 1988-2018. Os lagos foram agrupados por técnicas de agrupamento e estatística multivariada. A evolução de área dos lagos e geleiras foram estimadas por segmentação e Índice de Diferença Normalizada da Água (NDWI) em imagens Landsat e Sentinel e outros dados de sensores remotos orbitais. Os lagos que apresentaram maiores variações de área foram os alimentados por aporte de água de degelo glacial destacando-se as áreas livres de gelo associadas à retração das geleiras Wanda, Viéville, Znosco e Anna Sul (636\%, 214\%, 173\% e 110\%, respectivamente). As menores variações (83\%, 71\%, 68\%, 43\% e 20\%) ocorrem em lagos nas áreas livres de gelo associadas à retração das geleiras Baranowski, Polar Club, da calota de gelo da ilha Nelson, da geleira Fourcade e das áreas livres de gelo na península Fildes, respectivamente. Originaram-se 37 novos lagos no período 1988-2018. O aquecimento atmosférico, a retenção da água de degelo glacial e a coalescência de lagos pequenos influenciam nas mudanças ocorridas nos lagos marginais ao gelo em escala decadal.
\end{abstract}

Palavras-chave: retração glacial; lagos alimentados por geleiras; paraglacial

Abstract: This study aims to compare the glacial lake variation in 1988-2018 period by ice-free land sector in King George Island (KGI) and Nelson Island (NI). Lake sectors were grouped by multivariate statistics techniques. Areal lake and glacier evolution are estimated by Landsat and Sentinel images segmentation and NDWI (was obtained 68-77\% of the accuracy) and using others spaceborne remote sensing data. Wanda, Viéville, Znosco e Anna Sul ice-marginal lakes have increased by $636 \%$, $214 \%, 173 \%$ and $110 \%$, respectively. The lower variation $(83 \%, 71 \%, 68 \%, 43 \%$ and $20 \%$ ) were showed in lakes of the ice-free 
land areas exposed by shrinkage in Baranowski Glacier, Polar Club Glacier, NI ice cap, Fourcade Glacier and in Fildes Peninsula, respectively. Were detected the formation of 37 new glacial lakes in the 1988-2018 period. The climate warming, meltwater retention due glacier discharge and coalescence of small and shallow lakes too play important roles in ice-marginal lakes evolution at decadal-scale variations.

Keywords: glacial retreat; glacier-fed lakes; paraglacial

\section{Introdução}

Em resposta à tendência de aumento das temperaturas superficiais do ar na região da Península Antártica, desde 1950 (SIMÕES; BREMER, 1995; AQUINO, 1999; ROSA et al., 2009; ANDRADE et al., 2011; KEJNA; ARAZNY; SOBOTA, 2013; SIMÕES et al., 2015), vários estudos evidenciam a retração de geleiras nas últimas décadas (RAU et al., 2004; RIGNOT et al., 2013; COOK et al., 2014; COOK et al., 2016, PERONDI, 2018; PETSCH, 2018; ARIGONYNETO, 2001; AHLERT; SIMÕES; ARIGONY, 2002; CANA, 2016; OLIVEIRA, 2018). A retração das geleiras ocasionou um aumento nas áreas livres de gelo, expondo formas de relevo e depósitos, na área proglacial, gerando novos ambientes lacustres na superfície terrestre (ROSA et al., 2014). Estes lagos se desenvolvem à medida que as geleiras recuam, geralmente se formam em bacias esculpidas pela erosão glacial, depressões kettles, morfologias tectônicas que favorecem a retenção da água de degelo ou são formados pelo represamento ocasionado pelas morainas (NEDBALOVÁ et al., 2013; HECKMANN; MCCOLL; MORCHE, 2015).

O processo de retração de geleiras é responsável pelo aumento de área e número de lagos proglaciais (CARRIVICK; TWEED, 2013; KUNZLER et al., 2010) e dessa forma existem diversos tipos de lagos com tamanhos, origem e tempo de formação diferentes (CARRIVICK; TWEED, 2013). A formação, evolução e estabilidade de lagos proglaciais estão fortemente ligadas à dinâmica da geleira, à natureza do ambiente circundante, à dinâmica dos canais de água de degelo, ligações ao comportamento da geleira e às mudanças climáticas (QUESADA et al., 2006; CARRIVICK; TWEED, 2013).

É registrado o aumento significativo na dimensão e frequência dos lagos associados à regiões glaciais de alta montanha em todo o mundo, como na Groelândia (CARRIVICK et al., 2014), Andes (EMMER; VILÍMEK, 2013; COOK et al., 2016), Alpes (HUGGEL et al., 2002; EMMER et al., 2015), região do Himalaia-Karakoram-Tibete (BAJRACHARYA; MOOL, 2009; GARDELLE; ARNAUD; BERTHIER, 2011; AGGARWAL et al., 2017), Ásia central (JANSKY; ŠOBR; ENGEL, 2010; MERGILI; MÜLLER; SCHNEIDER, 2013) e Cordilheira Ocidental da América do Norte (CLAGUE; EVANS, 2002; EMMER et al., 2016). Os autores atribuem as mudanças à diversas causas, como a tendência de aquecimento atmosférico, à retração glacial e ao aumento da retenção do aporte de água de degelo glacial, coalescência além de variações nos fatores que levam o derretimento da neve sazonal.

O surgimento e evolução em área de lagos marginais ao gelo junto a geleira Baranowski foi relatado por Szilo e Bialik (2018), com base em imagens de satélite de diferentes anos. Cana (2016) reportaram o aumento de área dos lagos marginais ao gelo entre 2006 e 2011 na Península Potter. Porém, estudos sobre a evolução do número, área e volume dos lagos, das áreas livres de gelo, e as causas das variações é pouco documentada para os demais lagos das ilhas Nelson e Rei George.

O objetivo deste trabalho é comparar as variações dos lagos e geleiras apresentadas por diferentes setores de áreas livres de gelo nas ilhas Rei George (IRG) e Nelson (IN) no período 1988-2018.

\section{2. Área de Estudo}

As ilhas Rei George e Nelson fazem parte das 29 ilhas que compõem o arquipelágo das Shetlands do Sul, localizado à noroeste da Península Antártica. A ilha Rei George é a maior delas, possui uma área de $1.250 \mathrm{~km}^{2}$ e 80 $\mathrm{km}$ de comprimento (maior eixo), está orientada no sentido sudeste-nordeste e possui $15 \mathrm{~km}$ de largura (menor eixo) no sentido oposto. Situa-se entre as coordenadas $61^{\circ} 50^{\prime}$ e $62^{\circ} 15^{\prime} \mathrm{S}$ de latitude e $57^{\circ}$ 30' e $59^{\circ} \mathrm{W}$ de longitude. As áreas livres de gelo na ilha correspondem a menos de 10\% da área total (BREMER, 1998; ARIGONY-NETO, 2001; ROSA, 2012). Já a ilha Nelson possui uma área de $200 \mathrm{~km}^{2}$, e localiza-se entre as coordenadas $62^{\circ} 19^{\prime} \mathrm{S}$ e $62^{\circ} 16^{\prime} \mathrm{S}$ de latitude e $59^{\circ} 11^{\prime} \mathrm{W}$ e $58^{\circ} 51^{\prime}$ de longitude. O comprimento do maior eixo possui $20 \mathrm{~km}$ e está orientado no sentido leste-oeste. O comprimento do menor eixo é de $13 \mathrm{~km}$. 
Na ilha Rei George, Shetlands do Sul (Figura 1), foram analisadas as seguintes áreas livres de gelo: península Fildes, Barton e Potter, ambas voltadas para a baía Maxwell; as áreas livres de gelo nas margens das geleiras Windy, Baranowski, Znosco, Wanda e Viéville, voltadas para baía do Almirantado; e da Anna Sul voltada para baía Rei George no setor leste do campo de gelo Krakow. Na ilha Nelson, a análise compreende as penínsulas Stansbury e Harmonia e todas as áreas livres de gelo (Figura 1) geradas pela retração recente das bacias de drenagem que fluem a partir da calota de gelo da ilha Nelson.

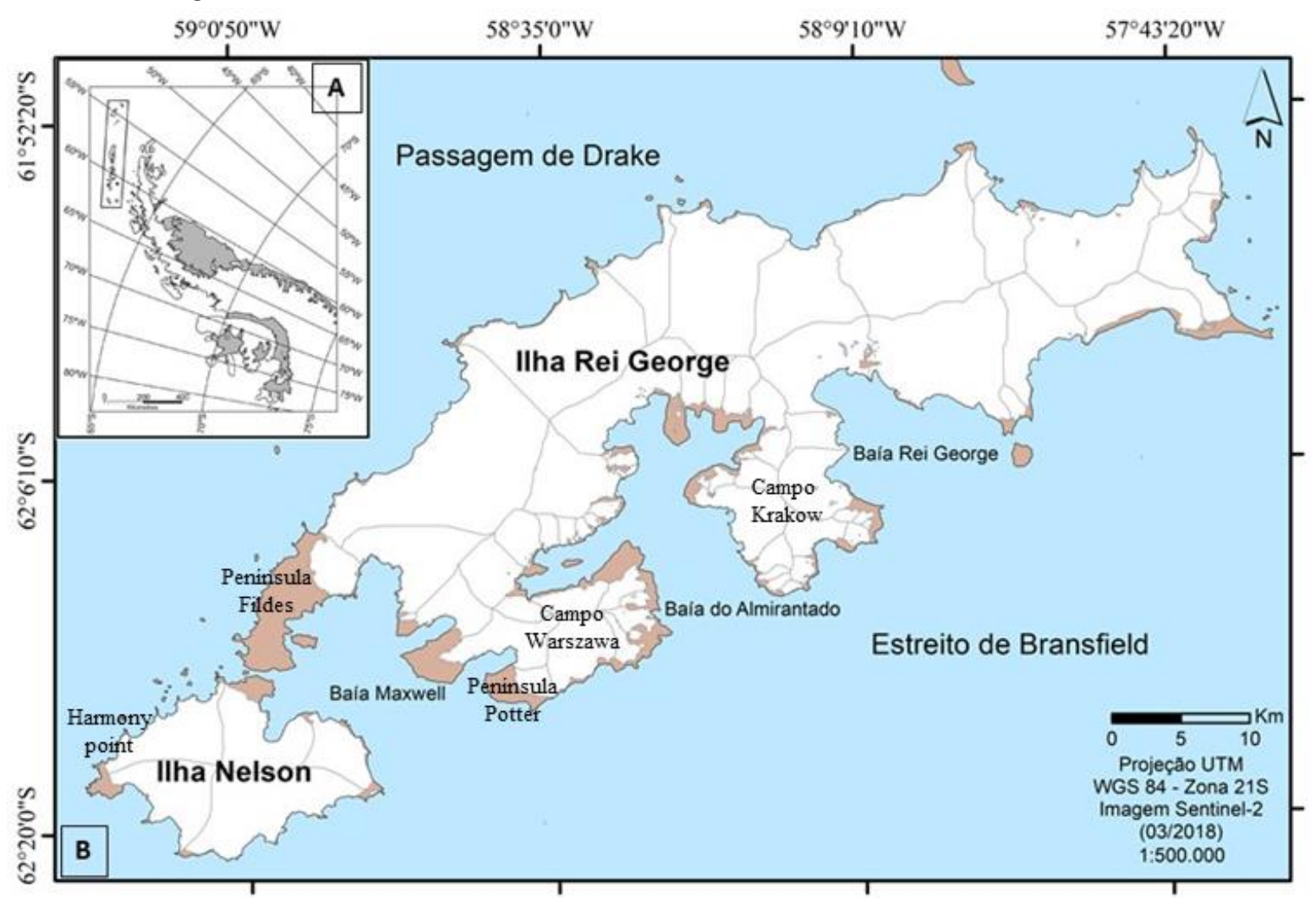

Figura 1: Localização das ilhas Rei George e Nelson (B) na Península Antártica (A). Base de dados GLIMS.

O embasamento do arquipélago é formado por rochas sedimentares, metassedimentares, vulcânicas e de suítes intrusivas formadas desde o período Pré-Cambriano até o Paleogeno e Neogeno (CURL, 1980). A área de estudo possui um clima tipicamente subpolar marítimo, pois sua localização geográfica está associada à região de baixa pressão circumpolar antártica. A precipitação na ilha Rei George é caracterizada pela alta variabilidade anual, uma média de 701,3 mm (1968-2011) (KEJNA; ARAZNY; SOBOTA, 2013) e a temperatura superficial do ar é caracterizada por uma média anual de aproximadamente $-1,5^{\circ} \mathrm{C}$. O mês de janeiro possui a maior temperatura observada $\left(2,4^{\circ} \mathrm{C}\right)$ e o mês de junho a menor $\left(-5,6^{\circ} \mathrm{C}\right)$ (observação em 2012) (SOBOTA; KEJNA; ARZANY, 2015).

\section{Materiais e Métodos}

\subsection{Banco de dados}

Foram utilizadas imagens de diferentes datas e satélites (Tabela 1) para o mapeamento dos lagos e das geleiras. Também foram utilizados dois Modelos Digital de Elevação (MDEs) (Tabela 1). Os dados de área de geleiras também foram obtidos de trabalhos de Oliveira (2018) (campo de gelo Kraków no período 1988-2018), Petsch (2018), Perondi (2018) (campo de gelo Warszawa no período 1988-2018), Arigony (2001) (na ASMA Baía do Almirantado no período de 1988-2000) e do GLIMS (Global Land Ice Measurements from Space). 
A partir das imagens pré-processadas também se foi aplicado o índice de diferença normalizada da água (NDWI) (MCFEETERS, 1996). O método do NDWI foi utilizado para segmentar o corpo d'água e a margem do lago, dos demais alvos do terreno (LI; SHENG; LUO, 2011). As equações do índice estão expostas a seguir:

NDWI (Landsat 5)= (b2 - b4) / (b2 + b4) (Equação 1) NDWI (Landsat 8)= (b3 - b5) / (b3 + b5) (Equação 2)

O método adotado para esta pesquisa foi baseado em Huggel et al. (2002), Li, Sheng e Luo (2011), Song et al. (2016) e Rai e Mishra (2017) utilizaram uma-abordagem integrada para delimitar os lagos de sua área de estudo, com delimitação visual somada as imagens segmentadas e dados de NDWI. Para as imagens de resolução espacial inferior a 10m (SPOT e Quickbird), a delimitação foi feita somente a partir de vetorização manual (WANG et al., 2011). Os MDEs Tandem-X e REMA 8 foram utilizados para criar uma máscara nas áreas de maior declive onde ocorreu a formação de sombras, retirando essas porções da delimitação dos lagos.

Foram construídos mosaicos de imagens, de diferentes datas, devido a presença de nuvens em algumas áreas livres de gelo, conforme metodologia de Nie et al. (2015). Sendo assim, as imagens representam um mapeamento que não se restringe a uma data específica, e sim a um período, entre 1988-1989, 2000-2003, 2015-2016 e 2018.

Tabela 1. Imagens utilizadas na análise de geleiras e lagos neste estudo.

\begin{tabular}{c|c|c|c|c}
\hline Dado & Data & Sensor & $\begin{array}{c}\text { Resolução } \\
\text { espacial (m) }\end{array}$ & Fonte \\
\hline Landsat 4 & $27 / 02 / 1988$ & TM & 30 & https://earthexplorer.usgs.gov/ \\
\hline Landsat 4 & $28 / 01 / 1989$ & TM & 30 & https://earthexplorer.usgs.gov/ \\
\hline Landsat 7 & $09 / 01 / 2003$ & ETM+ & 30 & https://earthexplorer.usgs.gov/ \\
\hline Landsat 7 & $28 / 01 / 2003$ & ETM+ & 30 & https://earthexplorer.usgs.gov/ \\
\hline Landsat 8 & $13 / 02 / 2015$ & OLI & 30 & https://earthexplorer.usgs.gov/ \\
\hline Landsat 8 & $19 / 03 / 2016$ & OLI & 30 & https://earthexplorer.usgs.gov/ \\
\hline Sentinel 2 & $01 / 03 / 2018$ & MSI & 10 & https://earthexplorer.usgs.gov/ \\
\hline Quickbird & 2011 & - & 2,8 & CPC \\
\hline SPOT & $23 / 02 / 2000$ & - & 10 & CPC \\
\hline TANDEM X & - & - & 12 (espacial) & $\begin{array}{c}\text { https://www.intelligence- } \\
\text { airbusds.com/optical-and-radar- } \\
\text { data/ }\end{array}$ \\
\hline REMA 8 & - & - & 8 (espacial) & $\begin{array}{c}\text { https://www.pgc.umn.edu/data/re } \\
\text { ma/ }\end{array}$ \\
\hline
\end{tabular}

\subsection{Interpretação da localização dos lagos}

Foi realizada a análise estatística multivariada, por agrupamento. $\mathrm{O}$ método utilizado foi hierárquico, com parâmetro de distância euclidiano e o número de agrupamentos estimado pelo software Action Stat. As informações utilizadas foram: tipo de lago (marginal ao gelo, ou seja, alimentado por aporte de água de degelo glacial pelo lago não alimentado por aporte de água de degelo de uma geleira), declividade, hipsometria, distância da geleira e do mar. Os parâmetros morfométricos foram gerados a partir dos MDEs utilizando a ferramenta slope e aspect do QGIS 3.4 .

\subsection{Medidas de área de lagos glaciais e geleiras}

Para aumentar a acurácia do mapeamento, seguiu-se a metodologia de Carrivick e Quincey (2014), a partir do qual_os arquivos de vetores do primeiro ano mapeado foram sobrepostos na data seguinte, dessa maneira foi considerado que não houve o desaparecimento de lagos. Essa técnica foi necessária devido a presença de gelo e neve encobrindo a superfície de lagos, em algumas imagens.

Para o cálculo da área das geleiras, foi utilizada a base de bacias de drenagem glacial do GLIMS. A partir desse arquivo vetorial, foram delimitadas as frentes das geleiras em 1988- 1989, 2000, 2003, 2011, 2015 e 2018, utilizando 
o método da interpretação visual. Atividades de campo de 2011, 2013 e 2019 possibilitaram evidenciar as características de alimentação do lago por água de degelo da geleira.

\subsection{Validação dos dados}

A validação dos dados foi realizada utilizando o plugin SCP do SIG QGIS 3.4. O índice de acurácia foi calculado tendo como verdade de campo os lagos georreferenciados em trabalhos de campo, realizados nas estações de verão de 2013, 2014 e 2015 (Figura 2).

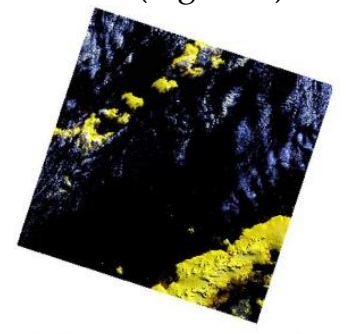

Pré processamento: *Reflectância

${ }^{*}$ Correção atmosférica
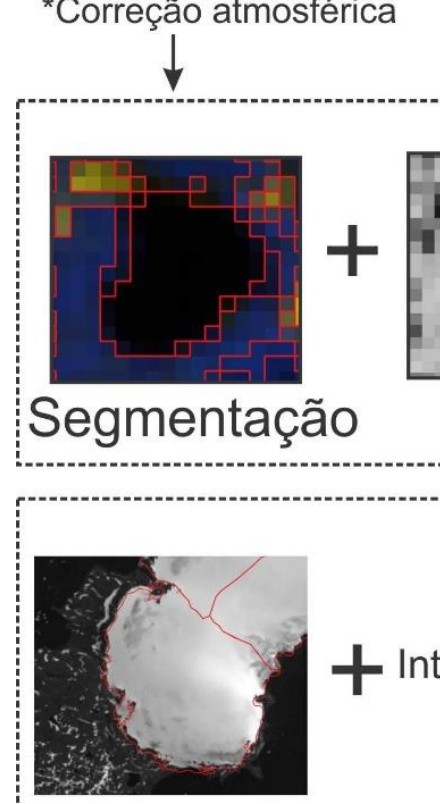

GLIMS

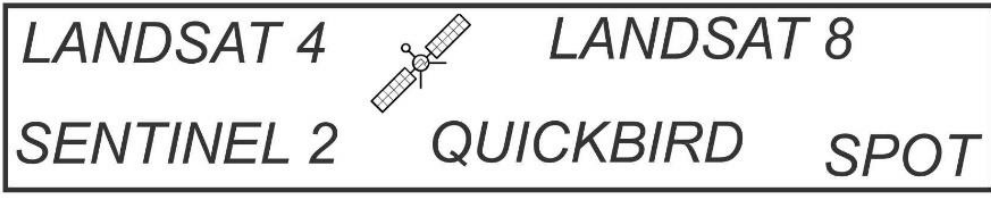

Análise da escala espacial e escolha das imagens
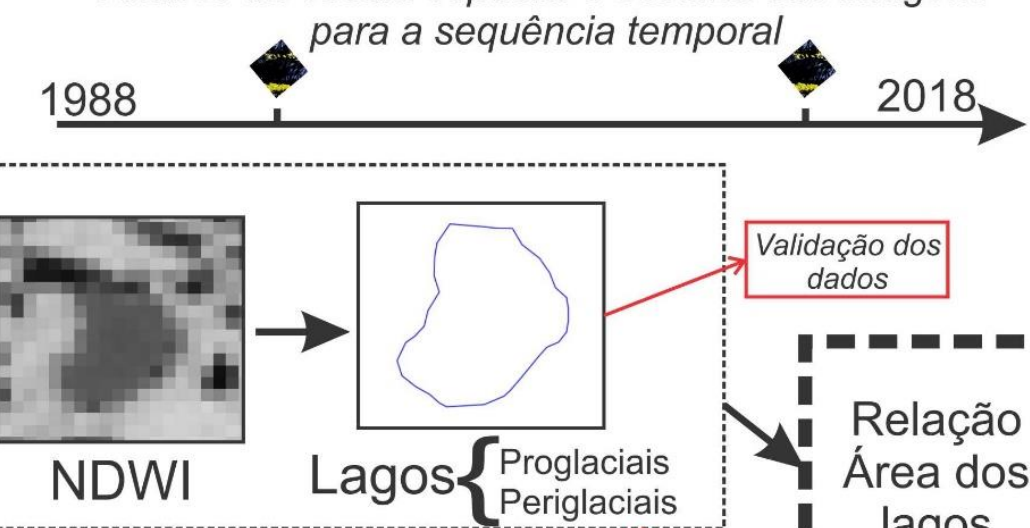

Validação dos dados
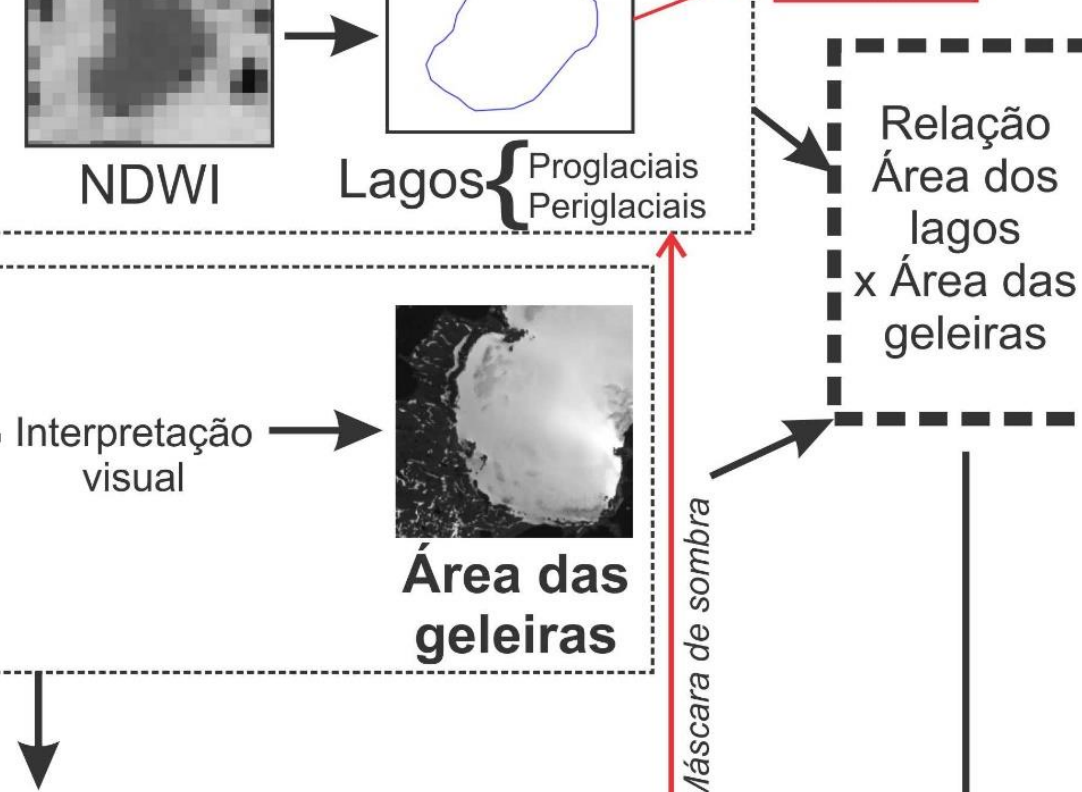

Análise multivariada (agrupamento):

*Distância da geleira;

*Distância do mar;

*Declividade;

*Hipsometria;

${ }^{*}$ Aspecto

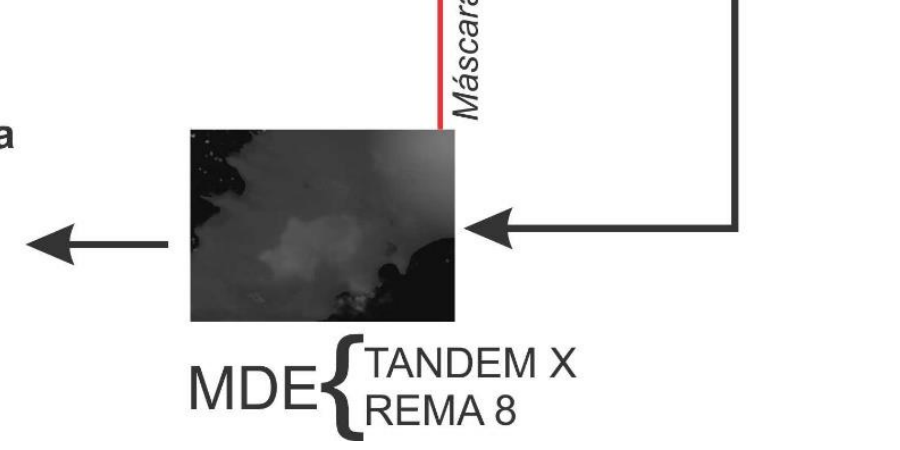

Figura 2. Fluxograma do método adotado para mapeamento da área e número de lagos, área das geleiras e análises ambientais. 


\section{Resultados}

\subsection{Calibração do método adotado para o mapeamento dos lagos glaciais e validação dos dados}

O uso de diferentes produtos de satélites implica em problemas ao comparar temporalmente dados obtidos com estas imagens (Figura 3). Alguns exemplos da limitação dos sensores serão apresentados a seguir. O lago Uruguai, localizado na península Fildes, teve uma variação de 0,44, 0,41, 0,60 e 0,65 km², respectivamente para os sensores do Landsat 8, Sentinel 2, Quickbird e SPOT. Essa variação de $21 \mathrm{~km}^{2}$, gera erros significativos e diminui a acurácia do mapeamento. Para a Ponta Harmony, ilha Nelson, a imagem Landsat 8 de 2016 permite_uma identificação de $0,244 \mathrm{~km}^{2}$ da área dos lāgos, e para a Sentinel de 2018 a área é de 0,079 km²; na península Stansbury a área mapeada com a imagem Landsat é de 0,053 e para Sentinel é de 0,060 km²; para a península Potter os lagos totalizam $0,33 \mathrm{~km}^{2}$ na Landsat e $0,30 \mathrm{~km}^{2}$ na Sentinel 2 . As diferenças podem variar significativamente, desde 0,007 $\mathrm{km}^{2}$ até $0,165 \mathrm{~km}^{2}$.

\section{IDENTIFICAÇÃO DE LAGOS EM IMAGENS DE DIFERENTES SENSORES DE SATÉLITES}
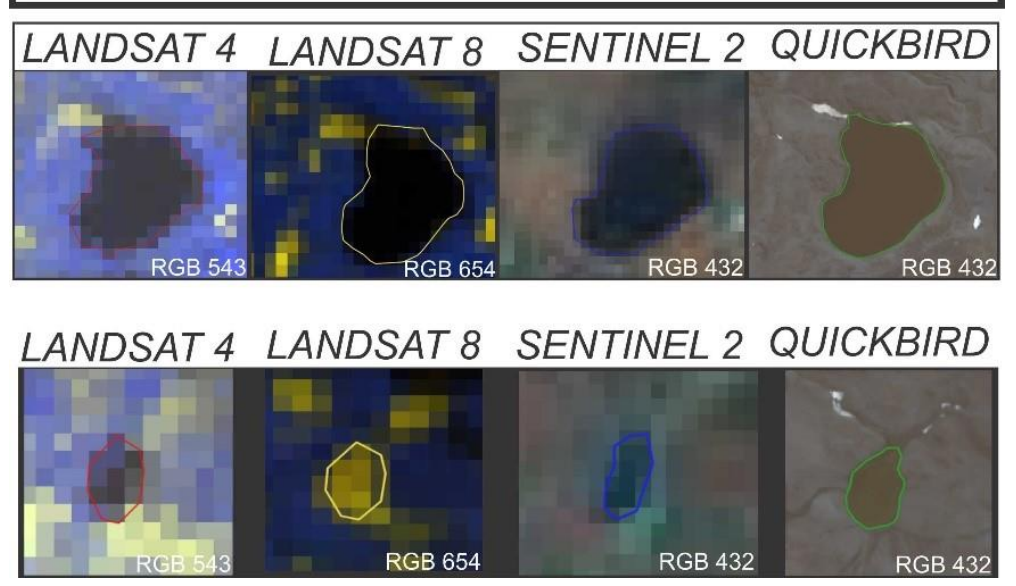

Figura 3. Delimitação dos lagos em imagens de satélite de diferentes escalas espaciais. Salienta-se que nas imagens da série Landsat foi difícil a vetorização manual das bordas dos lagos.

De forma geral, considerando os resultados obtidos com a segmentação das imagens Landsat e Sentinel, os lagos com áreas inferiores à $0,022 \mathrm{~km}^{2}$ não foram delimitados, o que provém principalmente da escala espacial adotada. Por outro lado, lagos com áreas superiores a $0,022 \mathrm{~km}^{2}$, como o lago Uruguai localizado na península Fildes, são delimitados através das duas técnicas, o que permite uma identificação da borda com melhor precisão. Considerando que os valores espectrais da superfície dos lagos possuem alta variação temporal, em função dos processos de congelamento e quebra do gelo, foi fundamental fazer a análise de cada imagem separadamente. Os valores abaixo de -0,15 foram considerados como prováveis de serem lagos para 1988 e 2016; valores menores de 0,55 foram adotados como possíveis áreas de lagos para a imagem de 2003, e valores abaixo de -0,20 para as imagens de 1988 e 1989. Relacionando os vetores de lagos obtidos com método integrante da segmentação e NDWI, foi obtida uma acurácia entre 70 e $81 \%$, quando comparado aos lagos georreferenciados em trabalhos de campo.

\subsection{Caracterização geomorfométrica dos lagos e agrupamentos gerados}

Na península Stansbury, ilha Nelson, a maioria dos lagos estão localizados em áreas caracterizadas pelos dados geomorfométricos: a) classe de elevação de 0-30 m, b) declividade entre 0-30\%, c) distância da margem da geleira de 1200-1600 m e do mar de 200-400m. Na península Harmony, ilha Nelson, os lagos se encontram em: a) elevações de 0-30 m, b) declividades entre 0-3\%, c) distância da geleira entre 0 e $100 \mathrm{~m}$. Os lagos na península Stansbury não sofrem influência direta da geleira, enquanto os lagos na península Harmony, são na maioria 
alimentados pelo aporte de água de degelo da geleira (com a exceção de um lago onde há maior distância da geleira $500-600 \mathrm{~m})$.

Na península Fildes, ilha Rei George, há 38 lagos com semelhanças quanto aos dados ambientais: a) em elevação entre 30 e $150 \mathrm{~m}$, b) declividade variada, c) distância mínima da geleira de $600 \mathrm{~m}$ e a máxima pode chegar a 7000, e por isto, são considerados não marginais ao gelo, ou seja, sem aporte de água de degelo da geleira. Contudo, destaca-se que esta é a área com maior número de lagos, o que implica em cinco diferentes agrupamentos dos lagos, segundo os dados geomorfométricos.

$\mathrm{Na}$ península Barton, quatro, dos cinco lagos existentes, apresentam: a) elevações de 120-150 m, b) declividades de 30-40\% e c) distância da margem glacial de 200-1700 m. Na península Potter, os lagos foram separados em 3 grupos, sendo que o grupo um é o maior em área total (com 5 lagos), o grupo dois com 3 lagos e o grupo três com 2 lagos. De forma geral, os lagos possuem: a) 30-60 m de elevação, b) declividade de 20-30\%, c) distância do mar de 100-200 m, d) orientação leste e sul.

No setor marginal ao gelo da geleira Anna Sul, os 3 lagos apresentam localização muito semelhante. Eles se encontram em altitudes de 0-30 m, estão em baixas declividades 0-7\%, e se encontram de 0-400 m de distância da geleira e todos com orientação sul.

Na baía do Almirantado, na área marginal ao gelo da geleira Baranowski, os seis lagos foram agrupados em dois grupos. O primeiro grupo contém 3 lagos com as mesmas características: a) classe de elevação de 0-30 m, b) declividades inferiores a 3\%, c) distância do mar entre 0 e 100, d) orientação leste. O segundo grupo de lagos apresentam: a) classe de elevação de 30-60, b) declividades inferiores a 3\%, c) entre 0 e100 m de distância da geleira d) orientação leste. Enquanto, nos ambientes marginais ao gelo das geleiras Wanda, Znosco, Windy e Viéville há: a) um lago por setor, b) ambiente marginal ao gelo e próximo ao mar, c) classe de elevação de 0-30 m e declividade baixa.

\subsection{Variação na área dos lagos e geleiras no período 1988-2018}

Os resultados possibilitaram observar um aumento nas áreas de diversos lagos estudados desde 1988 (Tabela 2; Figura 4). Estas variações são contrastadas com as flutuações das geleiras no mesmo período (1988-2018). Para a perda de área de geleira, período 1988-2018, os maiores valores foram no ambiente marginal ao gelo da geleira Viéville e ambiente marginal ao gelo da geleira Anna Sul, com 2,51 km² e 2,11 km². O menor valor estimado foi verificado na Península Barton, sendo de $0,18 \mathrm{~km}^{2}$ (Tabela 2).

Tabela 2. Variação na área de lagos e geleiras na área de estudo.

\begin{tabular}{c|c|c}
\hline Setores livres de gelo & $\begin{array}{c}\text { Aumento de área dos } \\
\text { lagos no período } \\
\mathbf{1 9 8 8 / 8 9 - 2 0 1 6 / 1 8} \mathbf{( \mathbf { k m } ^ { 2 } )}\end{array}$ & $\begin{array}{c}\text { Perda de área da } \\
\text { geleira } \\
\mathbf{1 9 8 8 / 8 9 - 2 0 1 6 / 1 8}\left(\mathbf{K m}^{\mathbf{2}}\right)\end{array}$ \\
\hline Península Fildes & 0,100 & 0,61 \\
\hline Península Barton & 0,025 & 0,18 \\
\hline Península Potter & 0,140 & 0,28 \\
\hline Ponta Harmony & 0,004 & 1,57 \\
\hline Stansbury & 0,023 & 2,11 \\
\hline $\begin{array}{c}\text { Ambiente marginal ao } \\
\text { gelo da geleira Windy }\end{array}$ & 0,230 & 0,98 \\
\hline $\begin{array}{c}\text { Ambiente marginal ao } \\
\text { gelo da geleira Znosco }\end{array}$ & 0,082 & 0,28 \\
\hline $\begin{array}{c}\text { Ambiente marginal ao } \\
\text { gelo da geleira Anna } \\
\text { Sul }\end{array}$ & 0,115 & 2,11 \\
\hline
\end{tabular}




\begin{tabular}{c|c|c}
$\begin{array}{c}\text { Ambiente marginal ao } \\
\text { gelo da geleira } \\
\text { Baranowski }\end{array}$ & 0,024 & 0,75 \\
\hline $\begin{array}{c}\text { Ambiente marginal ao } \\
\text { gelo da geleira } \\
\text { Viéville }\end{array}$ & 0,022 & 2,51 \\
\hline $\begin{array}{c}\text { Ambiente marginal ao } \\
\text { gelo da geleira Wanda }\end{array}$ & 0,059 & 0,51 \\
\hline
\end{tabular}

As penínsulas Harmony e Stansbury (IN) apresentam comportamentos diferentes, sendo que a primeira apresenta menores valores de retração de geleira $\left(1,5 \mathrm{~km}^{2}\right)$ e aumento de área de lago $\left(0,004 \mathrm{~km}^{2}\right)$, enquanto a segunda apresenta maior valor de retração da geleira $\left(2,11 \mathrm{~km}^{2}\right)$ e $0,023 \mathrm{~km}^{2}$ de aumento de área de lago (Tabela 2; Figura 4; Figura 7)).

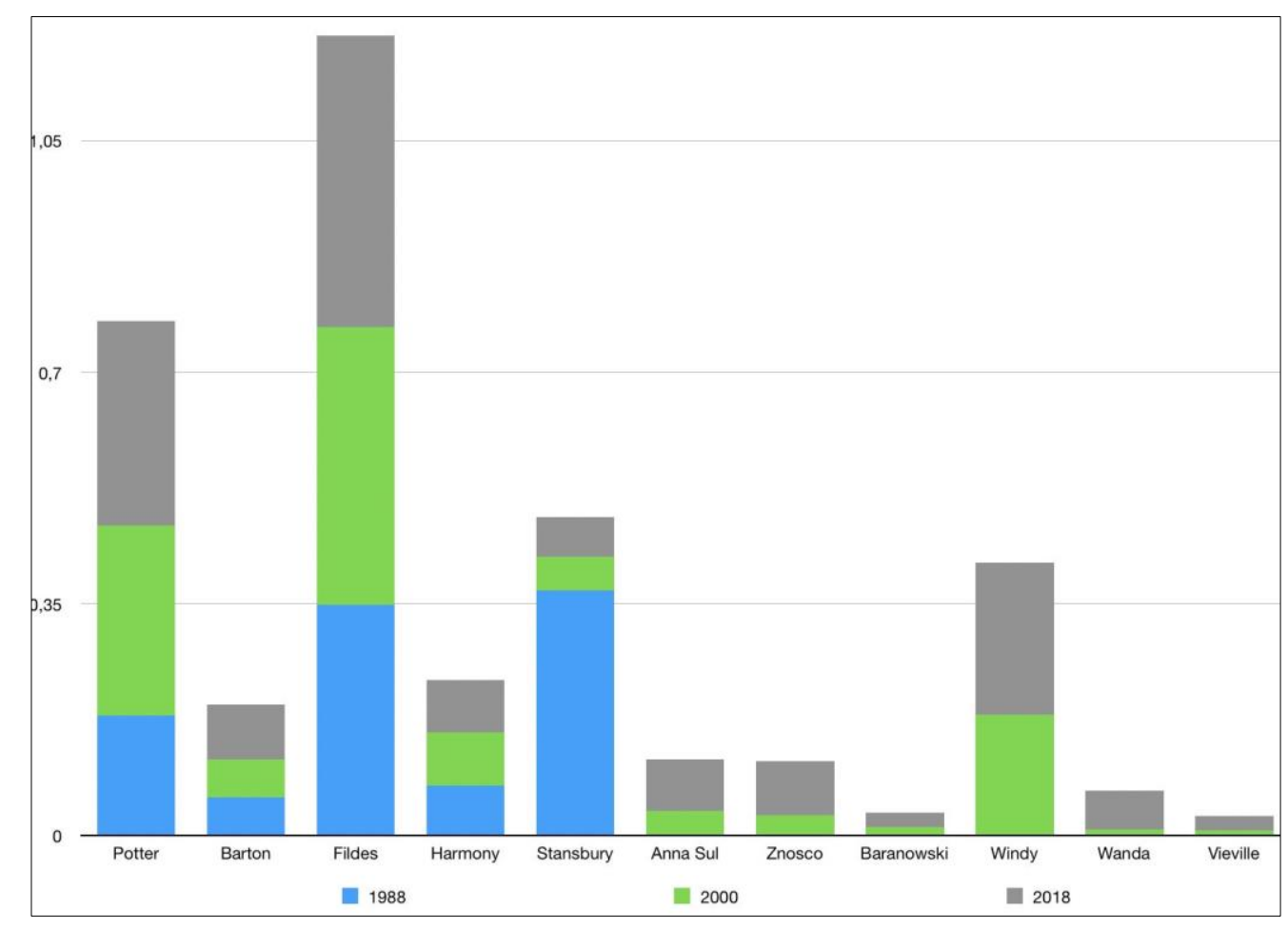

Figura 4. Comparação entre a variação na área dos lagos em áreas livres de gelo das ilhas Rei George e Nelson nos anos 1988/89, 2000/03 e 2016/18.

As penínsulas voltadas para a Baía de Maxwell (Potter, Barton e Fildes) (Figura 6), apresentaram maiores variações na área de lagos quando comparadas às áreas livres de gelo voltadas para a Baía do Almirantado (Figura 5) e para a baía Rei George (Tabela 2; Figura 5), exceto na frente da geleira Windy (onde os valores são altos). 


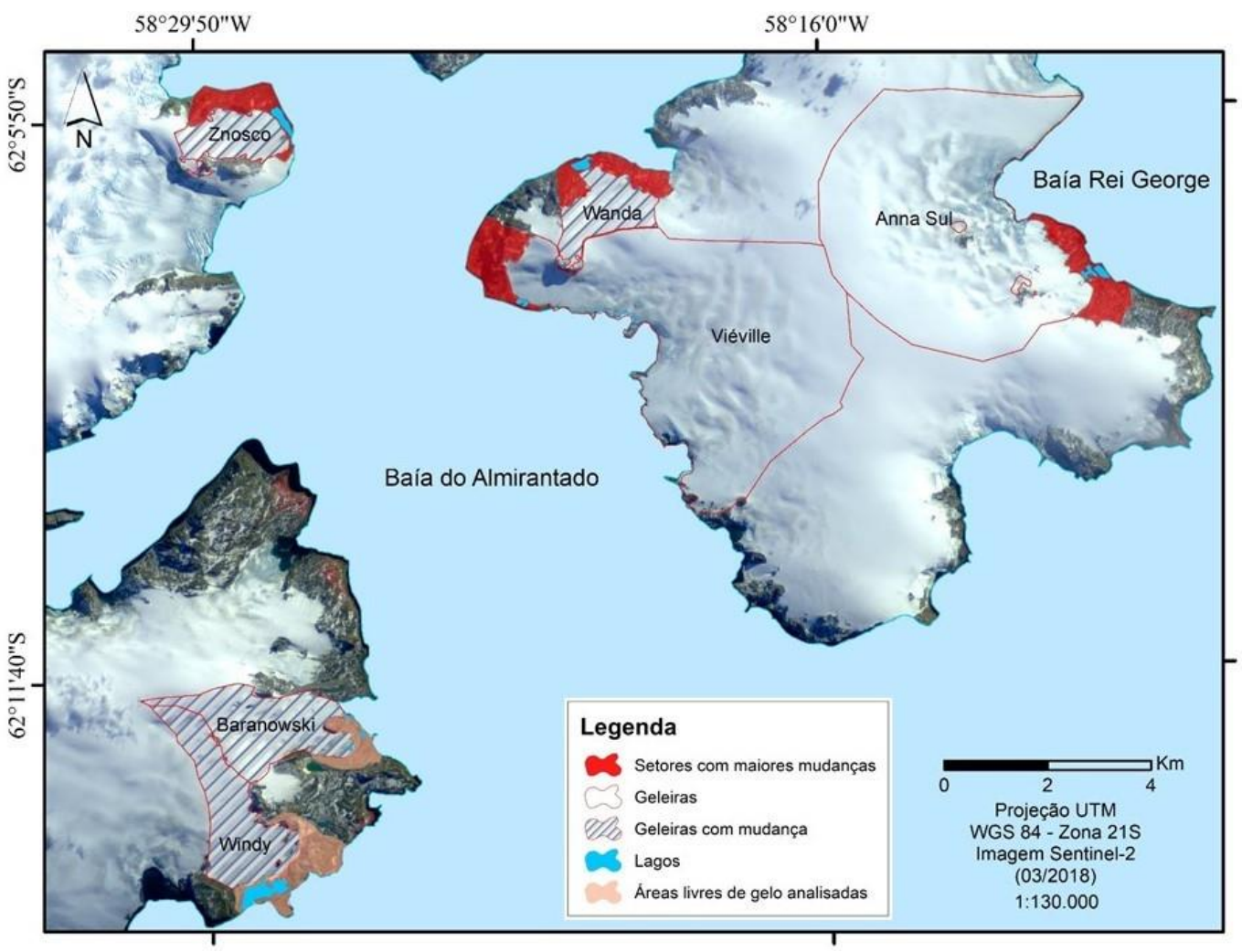

Figura 5. Mudanças nos lagos associados às geleiras voltadas para baía do Almirantado e Rei George.

Comparando a área de lagos das penínsulas Potter, Fildes e Barton, respectivamente o aumento foi de 0,140 $\mathrm{km}^{2}, 0,100 \mathrm{~km}^{2}$ e $0,025 \mathrm{~km}^{2}$ (Tabela 2; Figura 6). Porém, quanto se compara com os dados de retração das geleiras, verifica-se que a península Fildes possui o maior valor $\left(0,61 \mathrm{~km}^{2}\right)$ na geleira Collins, enquanto na península Barton foi registrado o menor valor de retração, na geleira Fourcade $\left(0,18 \mathrm{~km}^{2}\right)$.

Nas novas áreas livres de gelo da ilha Nelson (Figura 7) também foi possível evidenciar um aumento de lagos. Bacias de drenagens glaciais na ilha Nelson apresentaram uma retração de $12 \mathrm{~km}^{2}$ no período 1989-2018, representando uma perda de $7 \%$ da área. Os lagos alimentados por geleiras tiveram um aumento de 0,103 $\mathrm{km}^{2}$ (190\% da área de 0,054 km² de 1989), no primeiro período (1989-2003), e de 0,089 $\mathrm{km}^{2}$ ( $56 \%$ da área de 0,157 km² de 2003) no segundo período (2003-2018). 


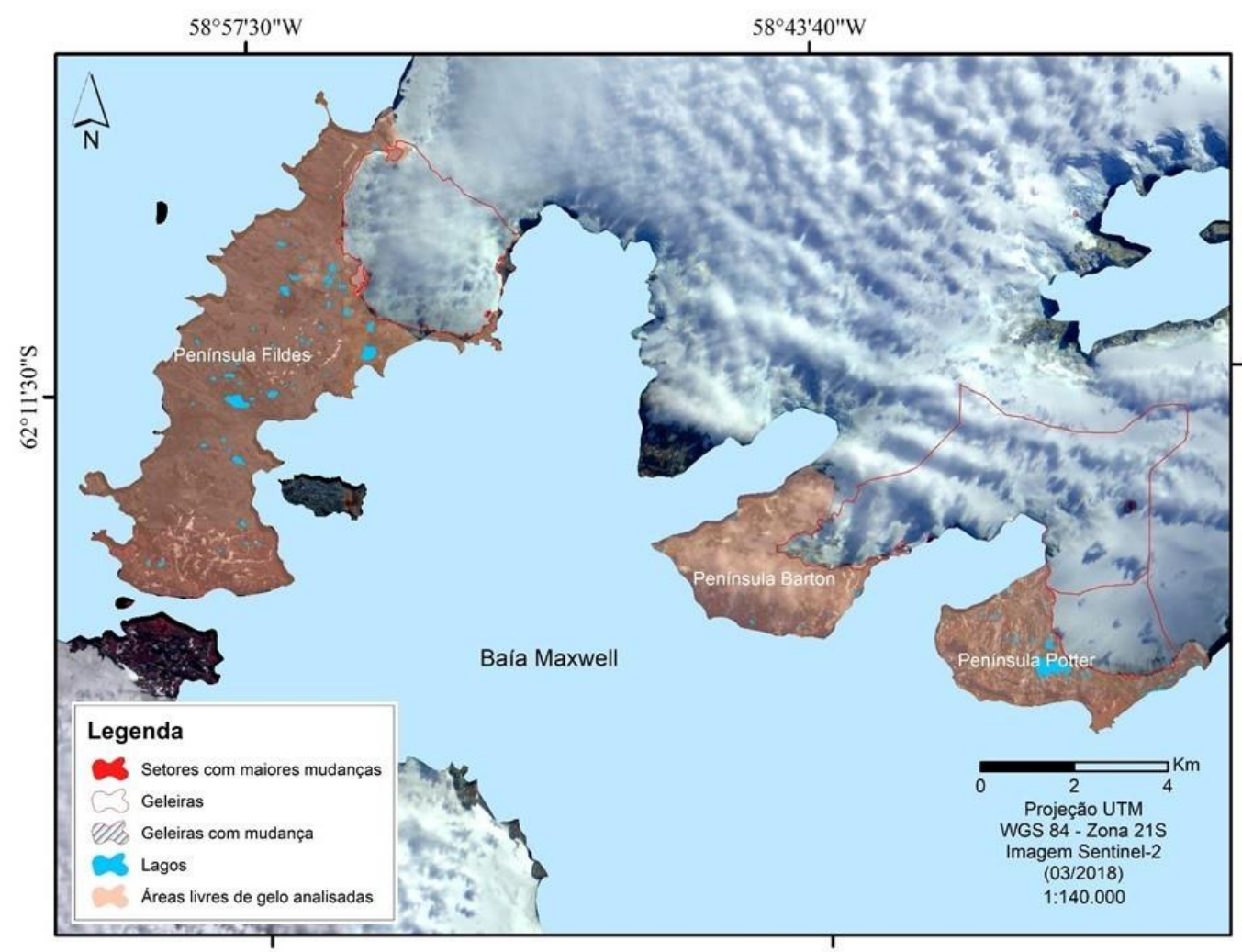

Figura 6. Mudanças nos lagos nas penínsulas Fildes, Barton e Potter.



Figura 7. Mudanças nos lagos na ilha Nelson. 


\section{Discussões}

As maiores variações percentuais das áreas de lagos ocorreram nas áreas livres de gelo associadas à retração das geleiras Wanda (636\%), Viéville (214\%), Znosco (173\%) - localizadas na baía do Almirantado - e Anna Sul $(110 \%)$, localizada na baía Rei George. As menores variações percentuais ocorreram em lagos das áreas livres de gelo associadas à retração da geleira Polar Club, na Península Potter (71\%); das bacias drenagens glaciais na ilha Nelson, Ponta Harmony e Stansbury e demais setores (68\%), da geleira Fourcade, na Península Barton (43\%), da geleira Windy (25\%) e das áreas livre de gelo na península Fildes (20\%).

As diferenças entre os contextos ambientais, dos setores aos quais os lagos estão inseridos, podem explicar os contrastes entre as variações de área apresentados pelos lagos para cada setor. Os lagos que apresentaram as maiores variações de área estão entre 0 e $30 \mathrm{~m}$ de elevação, com baixas declividades (0-7\%), e são alimentados por geleiras através de canais glaciofluviais ou em contato direto com a margem do gelo. Os setores, onde predominam lagos não alimentados por geleiras, apresentaram menores percentuais de expansão de suas áreas, o que se explica por esses lagos dependerem de precipitação líquida e degelo da neve.

A estrutura geológica e à presença de paleovales glaciais, podem estar influenciando na menor variação de número de lagos de alguns setores, quando comparado aos demais. Estas condições podem diminuir a possibilidade de coalescência de lagos, diferente dos setores mais planos (obtiveram aumento de área dos lagos e menor aumento no número de lagos, e.g. Wanda, Znosco e Windy, exceto Baranowski), onde são mais comuns os processos de coalescência dos lagos, em momentos de maior volume.

A Ponta Harmony e Stansbury, na ilha Nelson, apresentam lagos com maior distância da geleira e por isso já não recebem aporte de água de degelo. As demais áreas livres de gelo na ilha Nelson são recentes e possuem somente lagos alimentados por canais glaciofluviais. Zhang et al. (2015) também encontraram as maiores taxas de expansão nos lagos alimentados por geleiras em comparação com aqueles que não recebem mais aporte hidrológico.

As áreas recentemente expostas, nas geleiras Znosco, Anna Sul, Windy e Wanda, resultaram da transição da frente da geleira, de maré para terrestre, e os lagos se localizam em áreas de baixa declividade, elevação de 0-30 m, proximidade em relação ao mar e lagos conectados a geleira. A proximidade com a margem da geleira permite a alimentação do lago pela mesma em contato direto ou por canais glaciofluviais. Szilo e Bialik (2018) discutem que as geleiras com término no mar possuem uma maior sensibilidade às mudanças climáticas do que as geleiras de término em terra. Isso explica porque as áreas livres de gelo da península Fildes, Harmony e Potter estão mais estabilizadas, provavelmente devido ao fato de terem sua frente do tipo terrestre.

Os lagos na península Barton e Potter, que foram agrupados como da classe mais significante, estão sob maior influência do aporte de água de degelo da geleira e se concentram em elevações entre 120-150 m, apesar da grande variação dos demais dados de agrupamento. Para o setor marginal ao gelo da geleira Anna Sul, os lagos são todos alimentados por geleiras e se localizam próximos do mar e da geleira. Para os lagos que recebem aporte de água da geleira Baranowski, a única diferenciação no agrupamento provém da distância em relação ao mar, pois não há variações significativas dos aspectos morfológicos. Os lagos associados às geleiras Viéville, Wanda, Windy e Znosco são próximos à geleira e ao mar. Na Península Fildes não foram encontradas as mesmas relações estabelecidas para os demais setores, pois há uma série de pequenos agrupamentos, logo que os lagos se separam da margem glacial, o que ocorre em virtude da grande área livre de gelo e de várias características ambientais atuando na formação dos lagos.

Ressalta-se que considerando os dados de número de lagos para o período, houve aumento em todos os setores, mas os dados de variação de área dos lagos destacam as maiores elevações nos lagos associados às áreas livres de gelo da geleira Windy $\left(0,23 \mathrm{~km}^{2}\right)$ e da Ponta Stansbury $\left(0,023 \mathrm{~km}^{2}\right)$.

Ao analisar as variações nos lagos por período de tempo analisado (1988-2018), observa-se que estes respondem à flutuação das geleiras, as quais respondem as mudanças climáticas regionais (VAUGHAN et al. 2003; TURNER et al. 2014). Nas ilhas Nelson e Rei George, algumas bacias de drenagens glaciais eram de término marinho em 1988, que, após a retração nos últimos anos, passaram a expor feições morainicas, que represam a água de degelo e formam lagos. Muitos destes lagos podem ter aumentado por coalescência com a retenção do aporte 
de água de degelo, conforme afirma Carrivick et al. (2014). O autor discute que uma das consequências deste processo é o menor aporte de água e sedimentos para o oceano.

No que se refere a variação de área das geleiras, a península Stansbury, na ilha Nelson, apresentou um dos maiores valores de perda desde $1989\left(2,11 \mathrm{~km}^{2}\right)$. A geleira Baranowski é umas das que apresentou maior perda de área $\left(0,55 \mathrm{~km}^{2}\right.$ desde 1988), e nas recentes áreas expostas, houve formação de 6 lagos marginais ao gelo no período 1988-2018. A variação percentual de área nos lagos não é tão elevada, quando comparado aos demais setores analisados das ilhas. A diminuição de área de um dos lagos, verificada nos últimos anos, pode estar relacionada a eventos de extravasamento da água do lago situado mais próximo ao mar.

Com a retração prevista para as próximas décadas, novos lagos em contato com o gelo poderão surgir, e outros desaparecer diante do cenário futuro de continuidade da retração das geleiras nas Shetlands do Sul (e.g. RÜCKAMP et al., 2010; BARBOZA et al., 2004).

Ressalta-se que ao fazer uso de diferentes produtos cartográficos, com escalas espaciais diferentes, ocorrem limitações quando a quantificação dos dados. Salientamos que para a área de estudo, das Shetlands do Sul, a presença de nuvens e ausência de imagens de satélite gratuitas e com escala espacial adequada, acaba sujeitando a elaboração de pesquisas com um banco de dados com produtos diversos. Nesse sentido, visando diminuir os erros de mapeamento e aumentar a acurácia da classificação, optou-se por comparar a área e número de lagos provenientes de imagens Landsat somente para a península Fildes, Barton, Potter, Harmony e Stanbury. Para as áreas de Anna sul, Vieville, Wanda, Znosco, Baranowski e Windy foram utilizadas as imagens SPOT e Sentinel 2, visto que são lagos não mapeados na escala espacial de 30 metros apresentada pela série Landsat. As cartas topográficas de alguns setores disponíveis para a IRG possibilitaram verificar que estes lagos não existiam na década de 1980.

Ademais, a partir das dificuldades apresentadas para realizar a vetorização manual em imagens Landsat, foi adotada uma técnica integrada para classificação dos lagos (LI et al., 2011; SONG et al., 2016; HUGGEL et al., 2002; RAI; MISHRA 2017) associada à segmentação das imagens e aplicação do índice NDWI (Figura 11). Para as imagens SPOT e Quickbird foi adotada somente a técnica de vetorização manual, devido a facilidade de realizar a vetorização com a composição do visível. A validação dos dados se constituiu em um importante passo na comprovação da eficiência do método adotado, pela combinação da segmentação e NDWI. Gardelle, Arnaud e Berthier (2011), utilizando imagens Landsat, com o método integrado de NDWI e máscaras em áreas de sombra, chegaram a uma estimativa de erro de \pm 1 pixel ao longo do perímetro de cada lago. Carrivick e Quincey (2014) estimaram uma incerteza de $\sim 7 \%$ para lagos com $\sim 1 \mathrm{~km}^{2}$ e erro de $1 \%$ para lagos com $\sim 5 \mathrm{~km}^{2}$. Ressalta-se que o índice de acurácia desta pesquisa é significante, considerando a capacidade do método em identificar os lagos, com valores superiores a $70 \%$. Os valores de acurácia se modificam nas imagens em função da cobertura de gelo no lago, ou de mudanças espectrais nos alvos próximos ao corpo de água, o que dificulta a identificação da borda do lago.

\section{Conclusões}

Há contrastes entre as variações apresentadas pelos lagos e estas são explicadas pelas características ambientais de cada setor livre de gelo. Os maiores aumentos percentuais são nas áreas que foram recentemente expostas (desde 2000) pela retração glacial. Nestes setores, os lagos são conectados diretamente à geleira ou por canais glacifluviais e coalescem por se encontrarem em áreas planas com elevações que não passam de $30 \mathrm{~m}$. Já as áreas que registraram menores aumentos apresentam também algumas características ambientais importantes no entendimento desta dinâmica, ambas são áreas livres da ação glacial há mais tempo, a maioria dos lagos nestes setores estão afastados da geleira e não recebem aporte de água de degelo glacial, apresentam declividades variadas e elevações que podem chegar a $150 \mathrm{~m}$.

As variações nas geleiras e nos lagos servem como indicativo de mudanças nas geleiras e ainda mudanças na variabilidade climática local, são importantes no entendimento de modificações nos regimes de fluxo hidrológico em áreas livres. O aumento total de área de lagos nas áreas livres de gelo nesta região antártica poderá estar relacionado a uma possível maior estocagem de água e sedimentos no continente, variação no albedo, alterações no fluxo de metano e carbono e na biota local. 
Em setores de montanha os problemas podem ser pelo rompimento de morainas que mantém estes lagos represados fazendo com que haja riscos para populações à jusante. No caso da região antártica, os lagos podem aumentar em percentuais altos a medida que a geleira mantém conexão com ele, porém quando há distanciamento da frente da geleira este lago poderá perder a conexão, deixando de ser abastecido por ela, e passará a diminuir sua área e até mesmo desaparecer.

O sensoriamento remoto e as técnicas de SIG foram importantes no estudo de lagos marginais ao gelo, pois assim foi possível observar e monitorar o aumento em cada área e com isso buscar o entendimento da dinâmica das geleiras que abastecem estes lagos. Um dos desafios do mapeamento temporal de lagos na Antártica Marítima provém da disponibilidade de imagens sem cobertura de nuvens e da escala espacial dos sensores e por isso o banco de dados adotado para essa pesquisa foi necessariamente composto de imagens de diferentes escalas espaciais. Outra dificuldade encontrada é a influência atmosférica na resposta espectral dos alvos, por isso foi utilizada a segmentação para agrupar pixels com comportamentos espectrais similares, o que permitiu a identificação de uma série de alvos, entre eles as áreas de sombras, que foram também delimitadas a partir do MDE.

A aplicação da técnica de NDWI foi importante na validação dos dados, e por isso, o índice de acurácia encontrado foi adequado. Conforme a discussão apresentada sobre a questão da escala espacial das imagens satelitais utilizadas, pode-se afirmar que o resultado de aumento de área de lagos pode ser ainda maior. Imagens de satélite com resoluções de maior detalhe tornariam possíveis o mapeamento de outros lagos com áreas inferiores, e provavelmente evidenciariam um número maior de corpos hídricos.

Contribuições dos Autores: Manoela Araujo Gonçalves de Oliveira: Concepção; metodologia, validação; preparação de dados, escrita do artigo, Felipe Casanova: preparação de dados, Kátia Kellem da Rosa e Carina Petsch: Concepção; metodologia, revisão e supervisão, Rosemary Vieira e Jefferson Simões: revisão e supervisão. Todos os autores leram e concordaram com a versão publicada do manuscrito.

Financiamento: Esta pesquisa foi financiada pela CAPES (Coordenação de Aperfeiçoamento de Pessoal de Nível Superior), à primeira autora deste artigo, por meio de uma bolsa e do Programa de Pós-Graduação em Geografia da Universidade Federal do Rio Grande do Sul.

Agradecimentos: À Coordenação de Aperfeiçoamento de Pessoal de Nível Superior (CAPES). Ao Conselho Nacional de Desenvolvimento Científico e Tecnológico $(\mathrm{CNPq})$, ao PROANTAR, e à Fundação de Amparo à Pesquisa do Estado do Rio Grande do Sul (FAPERGS). Ao Centro Polar e Climático (CPC). Ao Programa de Pós-Graduação em Geografia (POSGEA) e à PROPESQ, UFRGS.

Conflito de Interesse: Os autores declaram não haver conflito de interesse.

Nota: Este artigo é parte da dissertação de mestrado do primeiro autor, Manoela Araujo Gonçalves de Oliveira (1) desenvolvida sob orientação de Kátia Kellem da Rosa (2) e defendida em 2020 no Programa de Pós-graduação em Geografia da Universidade Federal do Rio Grande do Sul.

\section{Referências}

1. AGGARWAL, S.; RAI, S.C.; THAKUR, P.K.; EMMER, A. Inventory and recently increasing GLOF susceptibility of glacial lakes in Sikkim, Eastern Himalaya. Geomorphology, v. 295, p. 39-54, 2017. DOI: 10.1016/j.geomorph.2017.06.014.

2. AHLERT, S.; SIMÕES J.C.; ARIGONY E. J. Monitoramento da calota de gelo da Ilha Nelson, Shetlands do Sul. In: X Seminário de Pesquisa Antártica, 10, 2002, São Paulo. Anais... São Paulo: USP. 2002. p. 6.

3. ANDRADE, A. M.; POELKING, E. L.; SCHAEFER, C. E. R.; FILHO, E. I. F.; JUSTINO, F. B. Mudanças climáticas regionais e seus reflexos nas variações da frente da geleira Polar Club, península Potter, Ilha Rei George entre 1986 e 2009. In: XV Simpósio Brasileiro de Sensoriamento Remoto (SBSR), 15, 2011, Curitiba. Anais... São José dos Campos: INPE. 2011. p. 5624-5631. ISBN 9788517000560

4. ARIGONY-NETO, J. Determinação e Interpretação de Características Glaciológicas e Geográficas com Sistema de Informações Geográficas na Área Antártica Especialmente Gerenciada Baía do Almirantado, Ilha Rei George, Antártica. Dissertação (Mestrado em Geografia) - Programa de Pós-Graduação em Geografia. Universidade Federal do Rio Grande do Sul, Porto Alegre. 2001. 98p. 
5. AQUINO, F.E. Sedimentação Moderna Associada à Geleira de Maré Lange, ilha Rei George, Antártica. Dissertação (Mestrado em Geografia) - Programa de Pós-Graduação em Geografia. Universidade Federal do Rio Grande do Sul, Porto Alegre, 1999. 106 p.

6. BAJRACHARYA, S. R.; MOOL, P. Glaciers, glacial lakes and glacial lake outburst floods in the Mount Everest region, Nepal. Annals of Glaciology, v. 50, n. 56, p. 81-86, 2009. DOI: 10.3189/172756410790595895.

7. BARBOZA, H. H. C.; BORTOLI, A. L.; SIMÕES, J, C.; CUNHA, R. D.; BRAUN, M. Bidimensional numerical simulation of Lange Glacier, King George Island, Antarctica: preliminary results. Pesquisa Antártica Brasileira, v. 4, n.1, p. 67-76, 2004.

8. CAÑA, B. B. Caracterização geomorfológica das áreas livres de gelo e flutuações na geleira Polar Club, Península Potter, Ilha Rei George. Dissertação (Mestrado em Sensoriamento Remoto) - Programa de Pós-Graduação em Sensoriamento Remoto. Universidade Federal do Rio Grande do Sul, Porto Alegre. 2016. 96p.

9. CARRIVICK, J.L.; TWEED, F.S. Proglacial lakes: character, behaviour and geological importance. Quaternary Science Reviews, v. 78, p. 34-52, 2013. DOI: 10.1016/j.quascirev.2013.07.028

10. CARRIVICK, J. L.; QUINCEY, D. J. Progressive increase in number and volume of ice-marginal lakes on the western margin of the Greenland Ice Sheet. Global and Planetary Change, v. 116, p.156-163, 2014. DOI: 10.1016/j.gloplacha.2014.02.009. 11. CLAGUE, J. J.; EVANS, S. G. 2002. A review of catastrophic drainage of moraine-dammed lakes in British Columbia. Quaternary Science Review, v. 19, n. 17-18, p. 1763-1783. DOI: 10.1016/S0277- 3791(00)00090-1

12. CONVEY, P.; PECK, L. S. Antarctic environmental change and biological responses. Science Advances, v. 5, n. 11, 2019. DOI: $10.1126 /$ sciadv.aaz0888.

13. COOK, A.; VAUGHAN, D.; LUCKMAN, A.; MURRAY, T. A New Antarctic Peninsula Glacier Basin Inventory and Observed Area Changes since the 1940s. Antarctic Science, v. 26, n.6, p. 614-624, 2014. DOI: 10.1017/S0954102014000200

14. COOK, A. J.; HOLLAND, P. R.; MEREDITH, M. P.; MURRAY, T.; LUCKMAN, A.; VAUGHAN, D. G. Ocean forcing of glacier retreat in the western Antarctic Peninsula. Science, v. 353, n. 6296, p.283-286, 2016. DOI: 10.1126/science.aae0017.

15. CURL, J.E. A glacial history of the South Shetland Islands, Antarctica. Ohio: Institute of Polar Studies Report, v. 63, n. $180,1980,129 \mathrm{p}$.

16. EMMER, A.; VILÍMEK, V. Lake and breach hazard assessment for moraine-dammed lakes: an example from the Cordillera Blanca (Peru). Nature Hazards Earth Systems Science, v. 13, p. 1551-1559, 2013. DOI: 10.5194/nhess-13-1551-2013.

17. EMMER, A.; LOARTE, E. C.; KLIMEŠ, J.; VILÍMEK, V. Recent evolution and degradation of the bent Jatunraju glacier (Cordillera Blanca, Peru). Geomorphology, v. 228, n.1, p. 345-355, 2015. DOI: 10.1016/j.geomorph.2014.09.018.

18. EMMER, A.; KLIMEŠ, J.; MERGILI, M.; VILÍMEK, V.; COCHACHIN, A. Lakes of the Cordillera Blanca: an inventory, classification, evolution and assessment of susceptibility to outburst floods. Catena, v. 147, p. 269-279, 2016. DOI: 10.1016/j.catena.2016.07.032.

19. GARDELLE, J.; ARNAUD, Y.; BERTHIER, E. Contrasted evolution of glacial lakes along the Hindu Kush Himalaya mountain range between 1990 and 2009. Global and Planetary Change, v. 75, n. 1-2, p. 47-55, 2011. DOI: 10.1016/j.gloplacha.2010.10.003.

20. GLIMS. Global Land Ice Measurements from Space. Disponível em: https://www.glims.org/. Acesso em: maio de 2018.

21. HECKMANN, T.; MCCOLL, S.; MORCHE, D. Retreating ice: research in pro-glacial areas matters. Earth Surface Processes and Landforms, v. 41, n.2, p.271-276, 2015. DOI: 10.1002/esp.3858.

22. HOWAT, I. M.; PORTER, C.; SMITH, B. E.; NOH, M. J.; MORIN, P. The Reference Elevation Model of Antarctica. The Cryosphere, v. 13, n. 2, p.665-674, 2018. DOI: 10.5194/tc-13-665- 2019.

23. HUGGEL, C.; KÄ̈̈B, A.; HAEBERLI, W.; TEYSSEIRE, P.; PAUL, F. Remote sensing based assessment of hazards from glacier lake outbursts: a case study in the Swiss Alps. Canadian Geotechnology Journal, v. 39, n.2, p. 316-330, 2002. DOI: 10.1139/t01-099.

24. JANSKY, B.; ŠOBR, M.; ENGEL, Z. Outburst flood hazard: Case studies from the Tien- Shan Mountains, Kyrgyzstan. Limnologica. v. 40, n.4, p. 358-364, 2010. DOI: 10.1016/j.limno.2009.11.013.

25. KEJNA, M; ARAZNY, A.; SOBOTA, I. Climatic change on King George Island in the years 1948 - 2011. Polish Polar Research, v. 34, n. 2, p. 213-235, 2013. DOI: 10.2478/popore-2013-0004

26. KHIM, B.; YOON, H.; KANG C.; ZHAO J. Holocene Variations of Organic Carbon Contents in Lake Langer of King George Island, South Shetland Islands, West Antarctica. Ocean and Polar Research, v. 26, n. 3, p. 507-514, 2004. DOI: 10.4217/opr.2004.26.3.507. 
27. KUNZLER M, HUGGEL, C; LINSBAUER, A; HAEBERLI, W. Emerging risks related to new lakes in deglaciating areas of the Alps. In: MALET, J.P.; GLADE, T.; CASAGLI, N. (Ed). Mountain Risks Bringing Science to Society. Strasbourg: CERG, 2010. p. 453-458

28. JAWAK, S. D.; MATHEW, J. Semi-automatic extraction of water bodies and roads from high- resolution QuickBird satellite data. Proceedings of Geospatial World Forum, 2011. 257p. DOI: 10.13140/RG.2.1.2242.9288

29. LI, J.; SHENG, Y.; LUO, J. Automatic extraction of Himalayan glacial lakes with remote sensing. Journal Remote Sensing, v. 15, n.1, p. 29-43, 2011. DOI: 10.3390/rs10121913

30. MERGILI, M.; MÜLLER, J. P.; SCHNEIDER, J. F. Spatio-temporal development of high- mountain lakes in the headwaters of the Amu Darya River (Central Asia). Global Planet. Change, n. 107, p. 13-24, 2013. DOI: 10.1016/j.gloplacha.2013.04.001

31. MCFEETERS, S. K. The use of the Normalized Difference Water Index (NDWI) in the delineation of open water features. International Journal of Remote Sensing, v. 17, n. 7, p.1425-1432, 1996. DOI: 10.1080/01431169608948714.

32. NEDBALOVÁ, L.; NÝVLT, D.; KOPÁČEK, J.; ŠOBR, M.; ELSTER, J. Freshwater lakes of Ulu Peninsula, James Ross Island, north-east Antarctic Peninsula: Origin, geomorphology and physical and chemical limnology. Antarctic Science. v. 25, n.3, p. 358-372, 2013. DOI: 10.1017/S0954102012000934.

33. NIE, Y; SHENG, Y; LIU, Q; LIU, L; LIU, S; ZHANG, Y; SONG, C. A regional-scale assessment of Himalayan glacial lake changes using satellite observations from 1990 to 2015. Remote Sensing of Environment, v. 189, p.1-13, 2015. DOI: 10.1016/j.rse.2016.11.008.

34. OLIVA, M.; ANTONIADES, D.; SERRANO, E.; GIRALT, S.; LIU, E.; GRANADOS, I.; PLARABES, S. The deglaciation of Barton Peninsula (King George Island, South Shetland Islands, Antarctica) based on geomorphological evidence and lacustrine records. Polar Record, v. 55, n.3, p. 177- 188, 2019. DOI: 10.1017/S0032247419000469.

35. OLIVEIRA, M.A.G. Processo de retração nas geleiras do campo de gelo Krakow, Ilha Rei George, Antártica. Trabalho de Conclusão de Curso (em Geografia) - Departamento de Geografia, Universidade Federal do Rio Grande do Sul, Porto Alegre, 2018. 100p.

36. PERONDI, C. Análise da evolução do ambiente proglacial das geleiras Ecology, Sphinx, Baranowski, Tower e Windy, Ilha Rei George, Antártica. Dissertação (Mestrado em Geografia) - Programa de Pós-Graduação em Geografia, Universidade Federal do Rio Grande do Sul, Porto Alegre, 2018, 123p.

37. PETSCH, C. Evolução hidro geomorfológica da zona proglacial da geleira Collins, Ilha Rei George, Antártica. Tese (Doutorado em Geografia) - Programa de Pós-Graduação em Geografia, Universidade Federal do Rio Grande do Sul, Porto Alegre, 2018. 120p.

38. QUESADA, V.; VINCENT, W.F.; KAUP, E.; HOBBIE, J.E.; LAURION, I.; PIENITZ, R.; LÓPEZ-MARTÍNEZ, J.; DURÁN, J.; KAUP, H. L. Landscape control of high latitude lakes in a changing climate. In: BERGSTROM, D. M. et al. (Ed). Trends in Antarctic Terrestrial and Limnetic. Dordrecht: Springer, 2006, p. 221-252.

39. RAI P. K., MOGAN K., MISHRA S., AHMAD A. MISHRA V.N. A GIS-based approach in drainage morphometric analysis of Kanhar River Basin, India. Applied Water Science, n. 7, p.217-232, 2017. DOI: 10.1007/s13201-014-0238-y

40. RAU, F.; MAUZ, F.; DE ANGELIS, H.; JAÑA, R.; ARIGONY-NETO, J.; SKVARCA, P.; VOGT, S.; SAURER, H.; GOSSMANN, H. Variations of Glacier Frontal Positions on Northern Antarctic Peninsula. Annals of Glaciology, v. 39, p. 525530, 2004. DOI: $10.3189 / 172756404781814212$

41. RIGNOT, E.; JACOBS, S.; MOUGINOT, J.; SCHEUCHL, B. Ice-shelf Melting around Antarctica. Science, v. 341, n. 6143, p. 266-270, 2013. DOI: 10.1126/science.1235798

42. ROSA, K. K.; VIEIRA, R.; FERRANDO, F. A.; SIMÕES, J. C.; 2009. Comparações entre os ambientes de deglaciação das geleiras Wanda e Ecology, ilha Rei George. Antártica. XVII Simpósio Brasileiro sobre Pesquisa Antártica, São Paulo. Livro de resumos do XVII Simpósio Brasileiro sobre Pesquisa Antártica, 17, São Paulo. Anais..., São Paulo: USP, 2009. p. 135-136.

43. ROSA, K.K.; FREIBERGER, V.L.; VIEIRA, R.; ROSA, C.A; SIMÕES, J.C. Mudanças glaciais recentes e variabilidade climática na ilha Rei George, Antártica. Revista Quaternary and Environmental Geosciences, v. 5, n. 2. p. 176-183, 2014. DOI: 10.1029/2007JD009094.

44. RÜCKAMP, M.; BRAUN, M.; SUCKRO, S.; BLINDOW, N. Observed glacial changes on the King George ice cap, Antarctica, in the last decade. Global and Planetary Change, v.79, n. 1-2, p. 99-109, 2011. DOI: 10.1016/j.gloplacha.2011.06.009 45. SHEVNINA, E.; KOURZENEVA, E. Thermal regime and components of water balance of lakes in Antarctica at the Fildes peninsula and the Larsemann Hills. Tellus A, v. 69, n. 1, 2017. DOI: 10.1080/16000870.2017.1317202

46. SLAYMAKER, O.; KELLY, R. E. J. The Cryosphere and Global environmental Change. Blackwell Publishing, 2007. 280p. 
47. SIMÕES, J. C.; BREMER, U. F. Investigation of King George Island ice cover using ERS1 SAR and SPOT imagery. Selper, v. 11, n. 1, p. 56-60, 1995.

48. SIMÕES, C. L.; ROSA, K. K.; CZAPELA, F.; VIEIRA, R.; SIMOES, J. C. Collins Glacier retreat process and regional climatic variations, King George Island, Antarctica. Geographical Review, v. 105, n. 4, p. 462-471, 2015. DOI: 10.1111/j.19310846.2015.12091.x

49. SOBOTA, I.; KEJNA, M.; ARZANY, A. Short-term Mass Changes and Retreat of the Ecology and Sphinx Glacier System, King George Island, Antarctic Peninsula. Antarctic Science, v. 27, n. 5, p.500-510, 2015. DOI: 10.1017/S0954102015000188

50. SZILO, J.; BIALIK R. J. Recession and Ice Surface Elevation Changes of Baranowski Glacier and Its Impact on Proglacial Relief (King George Island, West Antarctica). Geosciences, v. 8, n. 10, 2018. DOI: 10.3390/geosciences8100355.

51. TURNER, J.; BARRAND, N. E.; BRACEGIRDLE, T. J.; CONVEY, P.; HODGSON, D. A.; JARVIS, M.; JENKINS, A.; MARSHALL, G.; MEREDITH, M. P.; ROSCOE, H.; SHANKLIN, J. Antarctic climate change and the environment: an update. Polar Record, v. 50, n. 3, p. 237-259, 2014. DOI: 10.1017/S0032247413000296. 1

52. VAUGHAN, D.G.; MARSHALl, G. J., CONNOLlEY, W. M., PARKINSON, C., MULVANEY, R.; HODGSON, D. A.; KING, J. C.; PUDSEY, C. J.; TURNER, J. Recent Rapid Regional Climate Warming on the Antarctic Peninsula. Climatic Change, n. 60, p. 243-274, 2003 DOI: 10.1023/A:1026021217991.

53. WANG, X.; LIU, S. Y.; MO, H. W.; YAO, X. J.; JIANG, Z. L.; GUO, W. Q. Expansion of glacial lakes and its implication for climate changes in the Chinese Himalayaia. Acta Geographica Sinica, n. 144, p. 104-110, 2011. DOI: 10.11821/xb201107003

54. YANG, X. Variations of glacial lakes and glaciers in the Boshula mountain range, southeast Tibet, from the 1970 s to 2009. Annals of Glaciology, v. 52, n. 58, p. 9-17, 2011. DOI: 10.3189/172756411797252347

55. ZHANG, G., YAO, T., XIE, H., WANG, W., YANG, W. 2015. An inventory of glacial lakes in the Third Pole region and their changes in response to global warming. Global Planetary Change, v. 131, p. 148-157, 2015. DOI: /10.1016/j.gloplacha.2015.05.01

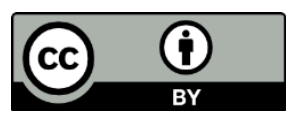

Esta obra está licenciada com uma Licença Creative Commons Atribuição 4.0 Internacional (http://creativecommons.org/licenses/by/4.0/) - CC BY. Esta licença permite que outros distribuam, remixem, adaptem e criem a partir do seu trabalho, mesmo para fins comerciais, desde que lhe atribuam o devido crédito pela criação original. 